\title{
The Partnership between a University and 5 Schools for Wise Use of Biodiversity
}

\author{
Kenichi Kanno (Corresponding author), Takeshi Hidaka, Tetsuo Kaneko, Hirofumi Kawazumi, Morio Karube \& \\ Youichi Kaneko \\ Faculty of Humanity-Oriented Science and Technology, Kinki University \\ 11-6 Kayanomori, Iizukashi, Fukuoka 820-8555, JAPAN \\ Tel: 81-948-22-5655Ｅ-mail: kanno@fuk.kindai.ac.jp
}

Shigefumi Toyofuku

Fukuoka Prefecture Tagawa High School, 2055-1 Nakatsuhara, Kawara, Fukuoka 822-1405, JAPAN

Toshiyuki Hirayama

Fukuoka Prefecture Kaisei High School, 122 Chojabaru, Kasuyacho, Fukuoka 811-2311, JAPAN

Rumiko Saiki

Fukuoka Prefecture Kurate High School, 810-7 Yamabe, Nogata, Fukuoka 822-0034, JAPAN

Yayoi Oda \& Keiji Nakanishi

Fukuoka Prefecture Hakuryou High School

4-47-1 Kashiwara, Minamiku, Fukuoka 811-1353, JAPAN

Keiji Nakaishi

Tokai University Daigo High School, 1-9-1 Taku, Munakata, Fukuoka 811-4193, JAPAN

Susumu Kobori \& Aki Hayata

Onga River Wetland Center, 1-1-1 Mizohori, Nogata, Fukuoka 822-0013, JAPAN

Received: January 26, 2011

Accepted: February 27, 2011

doi:10.5539/jsd.v4n3p94

This project was financed by the Japan Science and Technology Agency, Science Partnership Project, No. BD102025.

\begin{abstract}
Kinki University Fukuoka Campus coordinated with 5 high schools in Fukuoka prefecture, namely, Kaisei high school, Kurate high school, Hakuryo high school, Tagawa high school, and Tokaidai Daigo high school, to run a project called the Science Partnership Project (SPP). We took high school students to Hakata bay in Fukuoka prefecture to teach them about sustainable use of marine resources. We also ran experiments on how to efficiently use Ulva, an alga that has overgrown and results in green tide around the world. In order to make students aware of the Convention on Biological Diversity (CBD), the booklet of the secretariat of the CBD (SCBD) was used as an introductory textbook for the project. High school students who participated in the SPP program presented their findings at the 10th conference of the party to the convention on biological diversity interactive fair for biodiversity.
\end{abstract}

Keywords: Biodiversity, Advanced science, Partnership, Environmental education, Communication, Education, Public awareness (CEPA), Education for sustainable development (EDS) 


\section{Introduction}

The 'United Nations Decade on Biodiversity 2011-2020' started this year. Partnerships between universities and schools will be an important strategy for engaging in the 'Decade on Biodiversity'. In this report, we describe a partnership between a university and 5 schools for the purposes of environmental education as part of communication, education, and public awareness of biodiversity.

The year 2010 was an important year for sustainable development, because, at the 10th conference of the party of the convention on biological diversity (CBD-COP10) held in Nagoya, Japan, delegates from more than 100 countries agreed on the 'Nagoya Protocol' regarding access to genetic resources and the fair and equitable sharing of benefits arising from their utilisation. At CBP-COP10, delegates also agreed on the new strategic plan of the Convention on Biological Diversity (CBD), namely, the 'Aichi Target'. The Japanese government wants to implement these guidelines for science education at schools to provide students with knowledge and awareness of the importance of biodiversity (Japanese Ministry of Education, 2009). The year 2010 was a good opportunity to address biodiversity issues in Japan, because 2010 was the international year of biodiversity, and CBD-COP10 was held in Japan.

A study on 'The economics of ecosystems \& biodiversity (TEEB)' has revealed the importance of ecosystem services for economics (Bishop et al., 2010). Wise use of biodiversity is important for sustainable development, because ecosystem services are provided by biodiversity (The Millennium Ecosystem Assessment, 2005). Many kinds of scientific approaches for sustainable development are in progress, for instance, conservation of nature (Alvarez, 2010), chemical technology for recycling plastics (Chen, 2006), material science (Wu et al., 2009), and education for sustainable development (EDS) (Macris et al., 2006). We have focused on education for sustainable development. Wang et al. (2010) reported the importance of ecotourism education for sustainable development. Zhang et al. (2009) reported the efficacy of Green School, an international environmental education program conducive to saving energy and resources. In this paper, we describe the importance of partnerships between universities and schools for educating students about the wise use of biodiversity for sustainable development. Education plays an important role in the sustainability of biodiversity. Currently, in Japan, many institutes and groups are focusing on environmental education. Various people from various fields and positions are engaging in environmental education with creative approaches. Different groups with different backgrounds, including school teachers, research institutions, government administrations, non-profit organisations, companies, and at times conglomerates, are working together to ensure sustainable development.

Education aimed at future members of society, such as university and high school students, is also very important for sustainable development. However, because of economic considerations, it is also necessary for companies to gain knowledge on the importance of biodiversity, as achieving the CBD-COP10 targets will be difficult without their support and understanding. Thus, it is important to make an effort to educate people and create human resources who have acquired knowledge of biodiversity before working for a company. However, it is not easy to teach children and the youth about wise use of biodiversity, because appropriate consideration of biodiversity and ecosystem services must be included in many related areas of research, for instance, biology, agriculture, fishery, economy, recycling technology, and climate change. A partnership between a university and school may achieve such wide-scale education.

\section{Partnership between University and School}

The objective of this project was to teach youths the importance of biodiversity and encourage them to consider the sustainable use of ecosystem services. Algal, chemical, and biochemical experiments were used in this project, and the guiding principles of the Tbilisi declaration (Intergovernmental Conference on Environmental Education, Tbilisi, 1977) and the guidebooks for environmental education from the Commission on Education and Communication of the International Union for Conservation of Nature and Natural Resources and the secretariat of the CBD (SCBD) were employed (Stokking et al., 1999; Hesselink et al., 2007). As shown in scheme 1, the project consisted of 5 steps. Students learned about biodiversity, ecosystem services, and sustainable use of sea resources through a lecture and a practical excursion to Hakata bay. We used the SCBD booklet, entitled 'Invasive Alien Species-It's beside on you' as an introductory textbook to biodiversity, as this booklet is a good tool for imparting knowledge and awareness not only about biodiversity, but also about the CBD. To enable the use of this booklet by Japanese high school students, an undergraduate student, a high school student, a high school teacher, a non-governmental organization (NGO), and the SCBD worked together to translate the English booklet into Japanese (Kanno et al., 2009). The practical excursion was held at Hakata bay, because bays are good teaching resources for the sustainable use of ecosystem services. An important environmental problem at Hakata bay is the overgrowth of Ulva, which results in green tide. The technology 
involved in the utilisation of bio-resources and the cycling of waste, such as overgrowing Ulva, is important for sustainable development, as well as for the conservation of biodiversity. To examine the biodiversity problems at Hakata bay, the students performed 3 experiments involving the utilisation of Ulva, which is threatening the biodiversity of the bay. These experiments were summarised in an A4-formatted poster by the students themselves to be presented at the CBD-COP10 interactive fair for biodiversity.

\subsection{High school lectures}

At the 5 high schools, university researchers delivered a lecture on biodiversity, sustainable use of natural resources, SATOUMI, natural polysaccharides, and the CBD, among other topics. The SCBD booklet was used as the introductory textbook during these lectures for teaching the students about biodiversity and the CBD (Note 1).

\subsection{Learning about biodiversity and sustainable use of coastal seas at Hakata bay}

A total of 118 students came to Imazu, Hakata bay to learn about biodiversity, ecosystem services, and the sustainable use of sea resources. In 1998, Yanagi proposed a new concept for coastal sea management, 'SATOUMI', for the sustainable use of marine resources (Yanagi, 1998). Following the lecture about SATOUMI, the students saw many examples of such ecosystem services during the practical excursion, including Fukuoka Fisheries and the Marine Technology Research Centre. On the seashore, the students undertook a practical study on biodiversity, ecosystem services (such as food, habitat, and scenery), and the sustainable use of the sea. Students learned about the plants, animals, and habitats of Hakata bay, and were taught how various living things make up the diversity of life within the small bay area. It was explained how the ecosystem serves us, using examples such as oyster houses, which were familiar to most students: some people's livelihood in winter is supported by selling roasted oysters in a shack. Students observed eelgrass and learned why it is important and how it is related to other organisms, because fishes, crabs, and other living creatures are associated with the eelgrass habitat. The students noticed signboards posted on the seashore, depicting rules about fishing and the general use of the bay, which they were told contribute to the sustainable use of the sea.

The students observed Ulva, a green tide-forming alga. A proliferation of chlorophytes often causes green tides, and these blooms develop every spring and autumn on Fukuoka's coasts. In the research centre, a professor held a lecture about the red tide and green tide in Hakata bay to discuss how these occurrences threaten ecosystem services and biodiversity (Note 2).

\subsection{Experiments on the utilisation of Ulva at Kinki University}

In the laboratory, students discussed how to utilise the overgrowing Ulva. Many ideas were presented by the students. Ulva contains a sulphated polysaccharide, ulvan. Many researchers have reported various biological activities of ulvan, for example, anti-coagulant (Mao et al., 2009), anti-inflammatory (Leiro et al., 2010), and anti-hyperlipaemic effects (Pengzhan et al., 2003), among others. The students chose to examine the anti-coagulant activity of ulvan.

The utilisation of ulvan was examined as follows:

-Extraction of ulvan from Ulva

-Structural analysis of Ulva and ulvan

-Assessment of the anti-coagulant activity of ulvan.

\subsubsection{Extraction of ulvan from Ulva}

The most common method for extracting ulvan is hot water extraction. In this project, ulvan was extracted according to the method reported by Robic et al. (2008). The extraction process consists of the following steps: heating Ulva in hot water, filtrating residual Ulva, dialysis of the polysaccharide mixture, diethylaminoethyl (DEAE)-cellulose-column chromatography, and freeze-drying. In order to complete the experiment in 1 day, we prepared the samples for the each step, and the students experimented using those samples, because the extraction process takes a few days.

\subsubsection{Structural analysis of Ulva and ulvan}

Students observed the surface of Ulva with a scanning electron microscope (SEM), because they could not see the biological structure of Ulva with the naked eye. They operated the SEM by themselves and took pictures of the Ulva surface.

The chemical structure of the sulphated polysaccharide ulvan was examined by infrared analysis, nuclear magnetic resonance imaging, and circular dichroism spectrum analysis. Identification of the spectra was 
explained by the researcher. The spectra showed that the extract was indeed ulvan.

2.3.3 Anti-coagulant activity of ulvan

To assess the anti-coagulant activity of ulvan, activated partial thromboplastin time (APTT), prothrombin time, and calcium clotting time were calculated. APTT is often used for examination of anti-coagulant activity of sulphated polysaccharides, because sulphated polysaccharides inhibit internal coagulation mechanisms. Calcium clotting time is not used in laboratory tests, but this method is often used in biological experiments in schools, because it is convenient and relatively inexpensive. Ulvan showed anti-coagulant activity.

\subsubsection{Discussion about the utilisation of Ulva}

The utilisation of Ulva has been investigated in various institutes, and some results have shown that manure and biofuel can be made from Ulva. In the case of Hakata bay, Ulva occurs on reclaimed land. Students presented their own ideas for utilising Ulva; a few students suggested making environmentally friendly plastic bags from Ulva, because Ulva's smooth surface may include plastic materials (Note 3).

\subsection{Preparing a report at university}

Students summarised their study in a report, under instructions from a professor of a design course. Graduate and undergraduate university students supported the high school students during the preparation of the reports. The high school students placed photos of Hakata bay and the polysaccharide extraction experiment on the right side of an A4-formatted poster. They also included the results of the practical excursion and the experiment on the report. Students took their own photos with a PC-camera (Note 4).

\subsection{Presentation at the CBD-COP10 interactive fair}

The CBD-COP10 interactive fair for biodiversity was held at Nagoya Conference Centre from 18 to 28 October 2010. Students presented at the fair on 23-25 October and 26-28 October. All posters made by more than 100 students were mounted (Note 5). A few representative students from each high school presented the results of the project. It was a precious opportunity for students to discuss biodiversity with civilians, NGOs, and parties of the CBD. A report about the presentation and discussion at the CBD-COP10 interactive fair was prepared at each school (Note 6).

\section{Results and Discussion}

The SCBD booklet, entitled 'Invasive Alien Species-It's beside on you' was a good introductory textbook to biodiversity, because it imparts knowledge and awareness not only about biodiversity, but also about the CBD. The students, therefore, learned about the CBD and the convention for sustainable development through the textbook. Environmental education at Hakata bay was a good opportunity for students to learn about ecosystem services and sustainable use of the sea. The advanced science they were exposed to for the chemical utilisation of Ulva was also important for learning about bio-resources and ecosystems. Students discussed these experiments and prepared their own reports on computers at university. This was a unique opportunity for students to discuss both conservation and development. The students were able to share their ideas, for instance, 3 students proposed making plastic bags from Ulva, because the waxy layer and strength of Ulva is similar to that of a plastic bag. Students also were able to increase public awareness through presentation at the CBD-COP10 interactive fair for biodiversity and by sharing their newly acquired knowledge about the project at each high school.

Article 13 of the 'Text of The Convention on Biological Diversity' maintains that the contracting parties shall (Text of The Convention on Biological Diversity, 1992):

(a) Promote and encourage understanding of the importance of, and the measures required for, the conservation of biological diversity, as well as its propagation through media, and the inclusion of these topics in educational programs; and

(b) Cooperate, as appropriate, with other States and international organisations in developing educational and public awareness programs, with respect to conservation and sustainable use of biological diversity.

As explained by the SCBD, emerging from Article 13 of the convention, the program of work seeks to:

Communicate the scientific and technical work of the convention in a language that is accessible to many different groups;

Integrate biodiversity into education systems in all parties to the convention; and

Raise public awareness of the importance of biodiversity to our lives, as well as its intrinsic value.

In our project, by constructing a partnership between a university and 5 schools, we were able to integrate 
biodiversity into education and communicate the scientific and technical work of the convention to 5 schools. Through presentation at the CBD-COP10 interactive fair, students had the opportunity to raise public awareness of the importance of biodiversity to our lives. We had the advantage of having good teaching assistants, because most under-graduate university students who participated in the project as teaching assistants had previous experience as volunteers at elementary schools and high schools for environmental experiments or 'project WET activities' (Project WET Foundation). A partnership between a university and schools has many advantages, including the various areas of expertise of university staff, which results in various practical and examination experiences for the students, and the areas of expertise of the schoolteachers, which results in efficient environmental education.

\section{Acknowledgements}

The authors thank the Japan Science and Technology Agency 'Science Partnership Project' for financial support. We thank Ms. Junko Shimura and Ms. Noriko Moriwake of the Secretariat of the Convention on Biological Diversity (SCBD) for helping to translate the Textbook, Ms. Marie Aminata Khan of the SCBD for her informative lecture on the Convention on Biological Diversity, and Dr. Ahmed Djoghlaf, the Executive Secretary of the SCBD, for a letter of support for our project.

\section{References}

Japanese Ministry of Education, Culture, Sports, Science and Technology (Japanese Ministry of Education). (2009). Japanese Government Guidelines for Teaching (pp. 61).

Bishop, J., Bertrand, N., Evison, W., Gilbert, S., Grigg, A., Hwang, L., Kallesoe, M., Vakrou, A., Lugt, C., \& Vorhies, F. (2010). TEEB-The Economics of Ecosystems and Biodiversity Report for Business-Executive Summary.

The Millennium Ecosystem Assessment. (2005). WHO Libirary Cataloguing-in-Pablication Data, Ecosystems and Human Well-Being.

Alvarez, S. (2010). Journal of Sustainable Development, 3, 3-16.

Chen, C.-C. (2006). Environment International, 32, 478-486.

Wu, J., Zhao, J., Du, F., \& Han, Z. (2009). Journal of Sustainable Development, 2, 214-220.

Macris, A. M., \& Georgakellos, D. A. (2006). Journal of Cleaner Production, 14, 855-867.

Wang, X. (2010). Journal of Sustainable Development, 3, 261-263.

Zhang, J., Zhang, Z., \& Zheng, Y. (2009). Journal of Sustainable Development, 2, 200-203.

Intergovernmental Conference on Environmental Education, Tbilisi, USSR (14-26 October 1977). [Online] Available: http://unesdoc.unesco.org/images/0003/000327/032763eo.pdf (15 January 2011)

Stokking, H., van Aert, L., Meijberg, W., \& Kaskens, A. (IUCN) (1999). Evaluating Environmental Education.

F. Hesselink, Goldstein, W., Kempen, P. P., Garnett, T., \& Dela, J. (IUCN) (2007). Communication, Education and Public Awareness (CEPA): A Toolkit for National Focal Points and NBSAP Coordinators.

Kanno, K., Takahashi, S., Toyofuku, S., Hayata, A., Kawazumi, H., Tone, K., Hashizume, T., \& Shimura, J. (2009). Invasive Alien Species-it's besides on you. [Online] Available:

http://web.fuk.kindai.ac.jp/ biochem/idb\%20youth\%20jpn\%20210909.pdf (November, 2009)

http://www.cop10.jp/aichi-nagoya/biodiversity/pdf/idb-2009-youth-jpn-new.pdf (November, 2009)

Yanagi, T. (1998).Establishment of Sato-Umi in the coastal sea Journal of the Japan Society of Water Envrironment, 21, 703.

Mao, W., Li, H., Li, Y., Zhang, H., Qi, X., Sun, H., Chen, Y., \& Guo, S. (2009). International Journal of Biological Macromolecules, 44, 70-74.

Leiro, J. M., Varela, M., Piazzon, M. C., Arranz, J. A., Noya, M., \& Lamas, J. (2010). Molecular Immunology, 47, 1114-1120.

Pengzhan, Y., Ning, L., Xiguang, L., Gefei, Z., Quanbin, Z., \& Pengcheng, L. (2003). Pharmacological Research, 48, 543-549.

Robic, A., Sassi, J.-F., \& Lahaye, M. (2008). Carbohydrate Polymers, 74, 344-352.

Convention on Biological Diversity Text and Annexes, (1992), Article 13. Public Education and Awareness. 
[Online] Available: http://www.cbd.int/convention/articles/?a=cbd-13 (15 January 2011)

Project WET Foundation, Project WET (Water Education for Teachers)

\section{Notes}

Note 1 . The schedule of lectures at the 5 high schools:

May $17^{\text {th }}$, Tokai University Daigo High School, June $17^{\text {th }}$, Kurate High School, May $18^{\text {th }}$, Hakuryo High School, July $1^{\text {st }}$, Kaisei High School, July $3^{\text {rd }}$, Tagawa High School.

Note 2. The schedule of learning about biodiversity and sustainable use of coastal seas at Hakata bay:

July $27^{\text {th }}$, Tokai University Daigo High School, July $27^{\text {th }}$, Kurate High School, July $30^{\text {th }}$, Hakuryo High School, July $30^{\text {th }}$, Kaisei High School, July $27^{\text {th }}$, Tagawa High School.

Note 3. The schedule of experiments about the utilisation of Ulva at Kinki University:

July $29^{\text {th }}$, Tokai University Daigo High School, August $7^{\text {th }}$, Kurate High School, September $10^{\text {th }}$, Hakuryo High School, August $21^{\text {st }}$, Kaisei High School, July $29^{\text {th }}$, Tagawa High School.

Note 4 . The schedule of preparing reports at Kinki University:

August $21^{\text {st }}$, Tokai University Daigo High School, August $19^{\text {th }}$, Kurate High School, September $10^{\text {th }}$, Hakuryo High School, August $21^{\text {st }}$, Kaisei High School, September 11 ${ }^{\text {th }}$, Tagawa High School.

Note 5. The schedule of presentation at the COP10 interactive fair;

October 23-25, Tokai University Daigo High School, October 23-25, Kurate High School, October 26-28, Hakuryo High School, October 23-25, Kaisei High School, October 23-25, Tagawa High School.

Note 6 . The schedule of discussion at the 5 high schools;

October $23^{\text {rd }}$, Tokai University Daigo High School, November $7^{\text {th }}$, Kurate High School, October $27^{\text {th }}$, Hakuryo High School, January $28^{\text {th }} 2011$, Kaisei High School, February $24^{\text {th }}$ 2011, Tagawa High School.
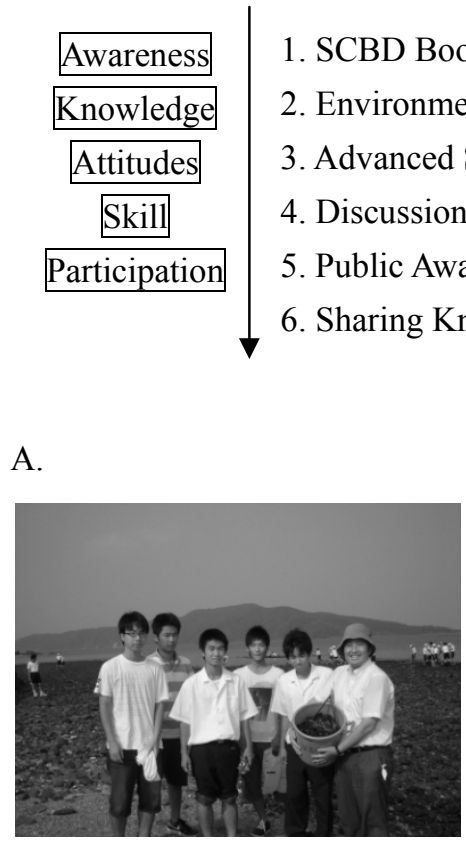

1. SCBD Booklet; Lecture on Biodiversity at the high schools.

2. Environmental Education; Sustainable Use of Sea; practice at Hakata bay.

3. Advanced Science for Recycling; Chemical Utilisation of Ulva at University.

4. Discussion; Making own reports with $\mathrm{PC}$ at university.

5. Public Awareness; Presentation at COP10 interactive fair for biodiversity.

6. Sharing Knowledge; presentation about the project at each high school.

Scheme 1. Strategy of the project

B.

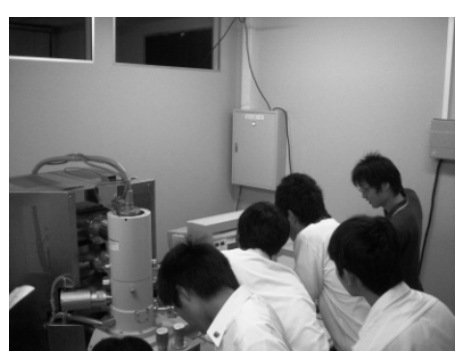

C.

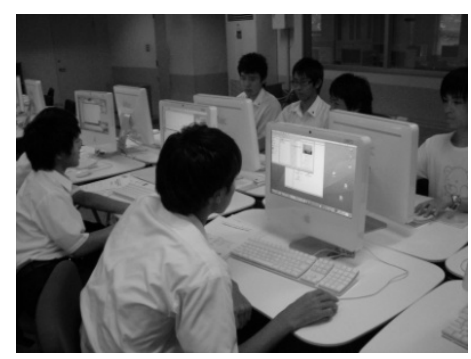

Figure 1. Environmental Education at Hakata bay and the University

A: Learning about biodiversity and the sustainable use of coastal seas at Hakata bay, B: Experiments about the utilisation of Ulva at University (SEM), C: Preparing a report at University. 


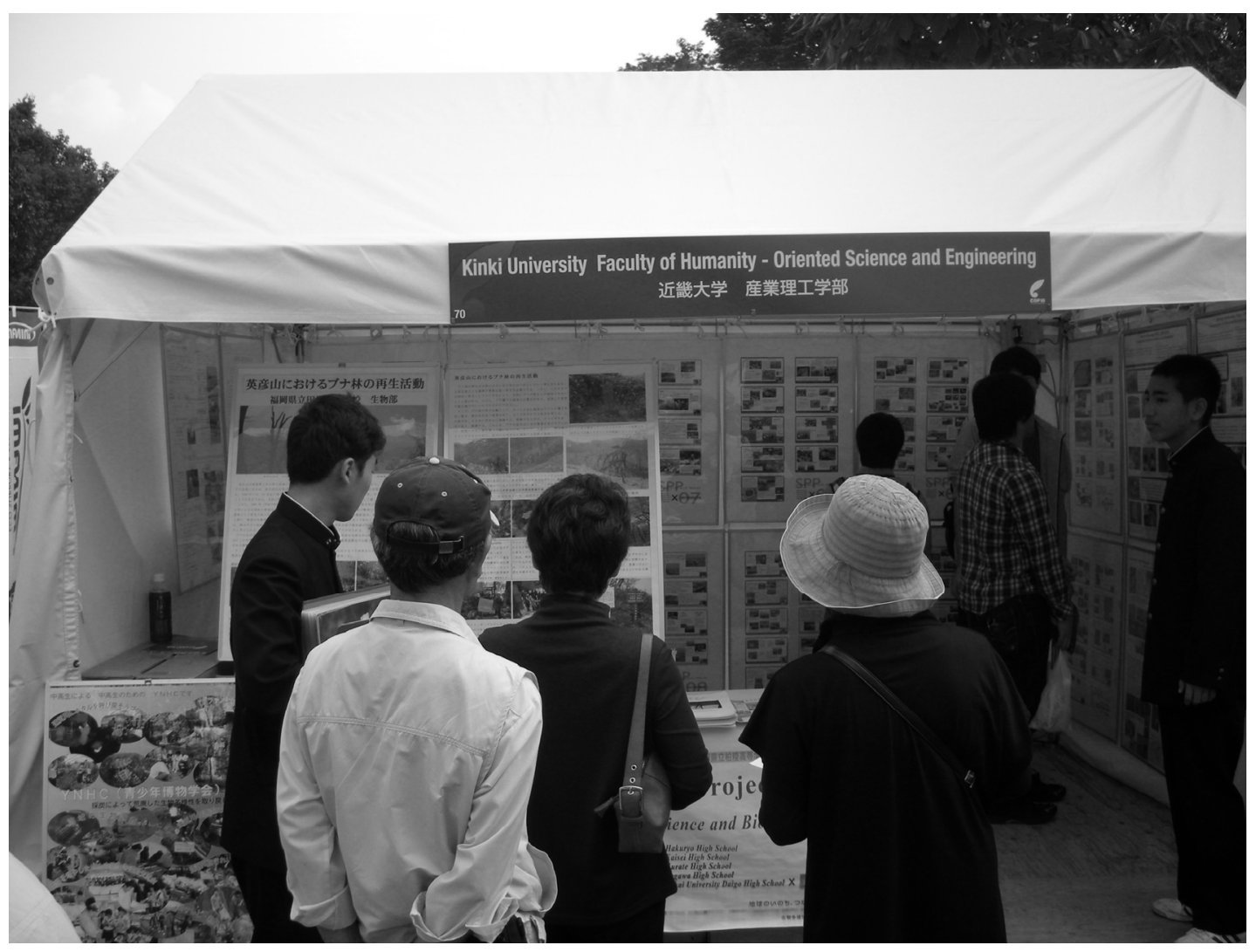

Figure 2. Presentation at the COP10 Interactive Fair for Biodiversity 